\title{
Chapter 21 \\ How Can Cognitive Neuroscience \\ Contribute to Mathematics Education? \\ Bridging the Two Research Areas
}

\author{
Roza Leikin
}

\begin{abstract}
This paper, which describes neurocognitive studies that focus on mathematical processing, demonstrates the value that both mathematics education research and neuroscience research can derive from the integration of these two areas of research. It includes a brief overview of neuroimaging research related to mathematical processing. I base my claim that cognitive neuroscience and mathematics education are still two tangent areas of research on a brief comparison of these two fields, with a particular spotlight on research goals, conceptions, and tools. Through a close look at several studies, I outline possible directions in which mathematics education and educational neuroscience can capitalize on each other. Mathematics education can contribute to the stages of research design, while neuroscience can validate theories in mathematics education and advance the interpretation of the research results. To make such an integration successful, collaboration between mathematics educators and neuroscientists is crucial.
\end{abstract}

Keywords Mathematics education research - Cognitive neuroscience Educational neuroscience $\cdot$ Mathematical processing

\subsection{Introduction}

In this paper, I analyze the potential contribution of neurocognitive research to the theory of mathematics education and exemplify some of its implications. This analysis is motivated by the following three observations:

First, there is no consensus among researchers that neuroscience has relevance for education. Educational neuroscience is seen as an emerging discipline with its roots in cognitive neuroscience and its focus on applying the findings of neuroscience to education and posing educational questions to be pursued in neurosci-

\footnotetext{
R. Leikin $(\bowtie)$

Department of Mathematics Education, RANGE Center - Research and Advancement of Giftedness and Excellence, University of Haifa, Haifa, Israel

e-mail: rozal@edu.haifa.ac.il

(C) The Author(s) 2018

G. Kaiser et al. (eds.), Invited Lectures from the 13th International Congress

on Mathematical Education, ICME-13 Monographs,

https://doi.org/10.1007/978-3-319-72170-5_21
} 
entific investigation (Geake 2009). In 1998, Byrnes and Fox suggested that brain research findings might have useful applications in education. Since then many researchers have supported this view with several theoretical hypotheses and have attempted to link neurocognitive empirical findings with the development of educational theory and practice. However, Bowers (2016) argued that there are still no examples of neuroscience motivating new and effective teaching methods, and further asserted that neuroscience is unlikely to improve teaching in the future.

Second, whereas some researchers (e.g., De Smedt et al. 2010), underscored the importance of "balanced dialogue" between neuroscience and education, Turner (2011) argued that this relationship is imbalanced, with a clear dominance of neuroscience (Clement and Lovat 2012). Furthermore, while De Smedt et al. (2010) maintained that neuroscience does not replace the need for behavioral studies, because behavioral studies may be needed to test conclusions drawn from neuroscientific observations, even in this argument behavioral studies and neuroscientific studies are not presented symmetrically. On the contrary, I argue that studies in the field of neuroscience can and should help in testing conclusions drawn from behavioral research in mathematics education. Consequently, research goals and research questions in neurocognitive research can be determined by the results of behavioral research, while behavioral studies can inform neuroscientific research vis-à-vis task design and research interpretations.

Third, mathematics education and cognitive neuroscience are two tangent areas of research. Even though a relatively large number of neurocognitive studies have been performed in the field of numerical cognition, these studies are rooted in cognitive psychology and are not connected to the findings of mathematics education research. Consequently, they use somewhat different terminology and have little impact on the processes of learning primary mathematics in school. Furthermore, only a small number of studies in cognitive neuroscience are currently exploring brain processing associated with (relatively) advanced mathematical concepts while these are rarely connected to theories in mathematics education.

Three notes:

(1) This paper does not provide a broad and detailed meta-analysis of research in the field or detailed descriptions of the studies observed, and it intentionally omits technical details related to the data collection and data analysis procedures of the reviewed research. Instead, it attempts to simplify complex information, present examples to illustrate the main ideas, and propose some directions through which research in cognitive neuroscience can contribute to the development of mathematics education as a scientific field.

(2) This paper does not address eye-tracking, a promising and interesting neuroscientific area of research. Implementation of eye tracking in mathematics education-e.g., in analysis proof reading (e.g., Andrá et al. 2015), exploration of problem-solving strategies (e.g., Obersteiner et al. 2014), and even examination of creative problem solving (e.g., Muldner and Burleston 2015) - has been developing exponentially. For example, the PME-40 conference included 
a relatively large number of presentations that applied eye tracking to the examination of mathematical processing at different levels (Csíkos et al. 2016).

(3) A glossary of technical terms in cognitive neuroscience can be found in the "Cognitive neuroscience and Mathematics Learning" special issue of ZDMMathematics Education 42(6) (Grabner et al. 2010a, b).

\subsection{Mathematics Education and Educational Neuroscience are Two Tangent Areas}

Even though neuroscientific research in the field of mathematical processing is making progress, some limitations to this research are still evident. De Smedt and Grabner pointed out that neuroscientific research is mostly performed with adult participants and requires better ecological validity. That is, many studies are performed in laboratory settings which are not similar to classroom settings in which students cope with tasks at different levels of mathematical challenge. In this section I argue that mathematics education and educational neuroscience are two tangent areas and illustrate this argument with the results of a brief search performed in several research outlets in the fields of cognitive neuroscience and mathematics education.

\subsubsection{Publications on Mathematical Processing in Cognitive Neuroscience Journals}

De Smedt and Grabner (2015) stress that "in the past decade, there has been a tremendous increase in neuroscience research on mathematics learning" (p. 2), while "the field of mathematics learning has been proposed as an ideal workspace for making applications of neuroscience to education" (p. 3).

I present herein a brief summary of publications in three journals in the field of cognitive neuroscience. I have chosen these particular journals according to their goals and scopes, which all include educational publications: Frontiers in Human Neuroscience, Neuropsychologia: An International Journal in Behavioral and Cognitive Neuroscience, and Trends in Neuroscience and Education. An analysis of a number of publications related to mathematical processing (at different levels of mathematics) during 2012-2016 demonstrated that despite researchers' growing interest in this area (reflected in Trends in Neuroscience and Education), the number of neuroscientific studies related to mathematical processing is very small. The search was made using the following key words: mathematics, arithmetic, numerical cognition, numerical operations, dyscalculia, algebra, calculus, and geometry. After this search, the papers were downloaded and compared in order to count only once those papers that came up repeatedly in the searches using different key words. The percentage of papers published in these journals varies 
significantly. During this period, in contrast to Frontiers in Human Neuroscience, where less than $1 \%$ of papers (19 of 2417) presented original research dealing with mathematical processing, 33\% (12 of 36) of original research papers in Trends in Neuroscience and Education included reports associated with research in mathematical processing. Overall, across the three journals, about $2.4 \%$ of all publications (including original research papers, review papers, and commentaries) were focused on various aspects of mathematical processing. No less interestingly, among the 105 articles (of 4375) in the same three journals, 92 papers (87\%) addressed numerical processing (including 18 articles on dyscalculia). Only a handful of studies explored brain activity related to mathematics studies in school.

\subsubsection{Neurocognitive Studies Published in Journals in Mathematics Education}

For analysis of publications in mathematics education journals, also during 20122016, I chose Educational Studies in Mathematics (ESM), Journal for Research in Mathematics Education (JRME), Mathematical Thinking and Learning (MTL), and Journal of Mathematical Behavior (JMB). The search, with a focus on original research papers, was conducted using the following key words pertaining to neuroscientific methodologies: EEG, ERP, fMRI, fNIRS, and eye tracking. I found only one publication, by Inglis and Alcock (2012), in JRME. This paper presented an investigation comparing expert and novice approaches to reading mathematical proofs using eye tracking methodology.

There are several possible explanations for the results of this search. First, I may have overlooked some publications (my apology if this is the case) and if so I would be glad to receive information from authors and readers who are familiar with such publications. Second, of the mathematics education researchers who consider these journals to be venues for publication of their findings, only a small number employ neuroscientific methodology in their studies. Third, those who do such research usually collaborate with neuroscientists, who prefer publishing their manuscripts in neuroscientific journals.

Fourth, there is another side of this coin. In my experience, reviews from neuroscientists and mathematics educators in response to the same publication had different foci of attention, and the requirements for revisions were contradictory to some extent. One of the central issues here is that, as I mentioned in the introduction, the implications of neuroscientific research for mathematics education are not straightforward, and it is difficult to explain the connections in a convincing way. The other central issue, which I describe in Sect. 21.4.1 of the paper, is the difference in theoretical frameworks and, correspondingly, in terminology and interpretation of findings, in the two fields. These issues are illustrated by the response that my colleagues and I received from the editor of one of the leading 
mathematics education journals (which I will call $X$ ) justifying why the paper was rejected without sending it to reviewers:

Articles published in $X$ journal pertain to the teaching or learning of mathematics and advance research in this area.... Although I read your paper with great interest, its findings do not move the field of research in mathematics education forward in clearly identifiable ways. (Editor)

The positions of the researchers in mathematics education and educational neuroscience are not contradictory but complementary, and thus bridges built between mathematics education and educational neuroscience can contribute meaningfully to the development of both fields. I argue that making connections between the two fields is a challenging task, and reviewers in both fields have to take greater care in presenting arguments that are compelling for researchers from a different discipline. In what follows, I demonstrate that research methods and tools are one of the reasons for tangency of the research in the two fields.

\subsubsection{Special Issues in Mathematics Education}

Fortunately, three special issues devoted to neuroscientific research related to mathematics education were published in two mathematics education journals. Two special issues were published in ZDM-Mathematics Education: one was "Cognitive Neuroscience and Mathematics Learning," edited by Grabner, Ansari, Schneider, De Smedt, Hannula, and Stern in 2010, and another was "Cognitive Neuroscience and Mathematics Learning: Revisited After Five Years," edited by Grabner and De Smedt in 2016. Another special issue edited by Anderson, Love, and Tsai, "Neuroscience Perspectives for Science and Mathematics Learning in Technology: Enhanced Learning Environments," was published in 2014 in the International Journal of Science and Mathematics Education (iJSME).

Most of the original papers in the iJSME special issue edited by Anderson et al. (2014) used eye-tracking techniques in research on processing related to mathematical and scientific concepts and processes. A paper by Norton and Deater-Deckard (2014) is one of two papers related to studies that investigated brain functioning associated with mathematical problem solving. The researchers take a neo-Piagetian approach to mathematical learning of fractions with computer games in order to frame two studies involving the use of EEG and FMRI techniques. Based on the neuroimaging data, the authors arrive at conclusions about the memory and attention mechanisms involved at different task levels.

The two $Z D M$ special issues revealed a significant increase in the variety of topics under investigation. The 2016 ZDM special issue contains articles on an impressive diversity of topics - including fraction comparison, geometry, arithmetic, and artificial symbol learning, to name just a few. In comparison to the state of the art in 2010, a more diverse set of questions pertaining to mathematics 
education is being investigated from a cognitive neuroscience perspective. This represents significant and exciting progress (Ansari and Lyonsi 2016, p. 380).

There was also an obvious shift in the methodology used-from fMRI investigations only to studies that employed a variety of neuro-cognitive techniques: fMRI, EEG (ERD), and ERP. In 2010, the ZDM special issue included eight original research papers, three overview manuscripts, and a glossary of terms. In 2016, the special issue included nine papers presenting original research and three commentary papers. As a critique, Ansari and Lyonsi (2016) pointed out that most of the studies published in both special issues presented experiments that had adults as the research participants and included "well-controlled psychological experiments, but their connections to the educational context and the mathematics classroom are unclear" (p. 380). This argument supports my observation that these two research areas are still tangent. However, I am certain that mathematics educators can find a wealth of exciting and useful information in these studies that can help in understanding the underlying processes of mathematical cognition, problem solving under different stress conditions, and neuroimaging aspects related to intuitive rules (see Sect. 21.4 in this paper).

\subsection{Neuroimaging Research Associated with Mathematical Processing: A Brief Overview of Issues Mathematics Education Research Does not Address}

Neuroimaging research focuses on the underlying brain structures (the magnitude of brain activation as well as brain topographies) associated with different types of mental activities in different population groups. A variety of neuroimaging techniques (for definitions, see Grabner et al. 2010a, b) allow researchers to obtain high-quality information on both temporal and spatial brain activity associated with different kinds of information-processing, including mathematical processing at different levels in individuals with varying levels of abilities. For example, the event-related brain potentials (ERP) technique offers high temporal resolution over the course of problem solving due to a precise reflection of perceptive and cognitive mechanisms. ERPs are electrophysiological measures that reflect changes in the electrical activity of the brain in relation to external stimuli and/or cognitive processes. These measures provide information about the process in real time, before the appearance of any external response (Neville et al. 1993). Another major technique is functional magnetic resonance imaging (fMRI), which offers high spatial resolution and enables the detection of differences in processing that are not evident from behavioral and ERP measures alone, thereby potentially leading to a more comprehensive understanding of the underlying processes and brain structures involved. 


\subsubsection{Localization of Brain Activation Associated with Mathematical Processing}

As mentioned, neuroimaging research focuses on localization of brain activation associated with mathematical processing and its relationship to general cognitive abilities (e.g., memory and attention). One example can be seen in the triple code theory of numerical knowledge, which emphasizes the role of the parietal cortex in number processing and arithmetic calculations (Dehaene et al. 2003) and identifies three regions of the parietal cortex that have been linked to the different functions connected to number processing. The horizontal intraparietal sulcus (HIPS) has been found to be involved in calculations; the posterior superior parietal lobule (PSPL) has been linked to the visuospatial and attention aspects of number processing (Dehaene et al. 2003); the angular gyrus (AG) has been found to be involved in the verbal processing of numbers and in fact retrieval (Grabner et al. 2009). Additionally, the parietal cortex has been found to be associated with word-problem solving (Newman et al. 2011), algebraic equations (Sohn et al. 2004), and geometry proof generation (e.g., Anderson et al. 2011).

Another example can be found in studies that show that the posterior superior parietal cortex is involved in visuospatial processing, including the mental representations of objects and mental rotations (Zacks 2008), while the frontal cortex has been linked to attention-control processes (Badre 2008) and working memory (Gruber and Von Cramon 2003). Solving of (relatively) advanced mathematical problems, such as calculus integrals, was found to activate a left-lateralized cortical network (Krueger et al. 2008).

Research on mathematical problem solving associated with different representations of mathematical objects is also a focus of neuroscientists. For example, different brain areas are known to be involved in recalling different representations of the functions (verbal vs. equation representations) and are thus connected to different cognitive processes involved in the corresponding mathematical processing (Sohn et al. 2004). Lee et al. (2007) compared brain activation in diagrammatic and equation representations for mathematical word problems and found that both modes of representation were associated with activation of areas linked to working memory and quantitative processing (the left frontal gyri and bilateral activation of HIPS). However, the symbolic representation activated the posterior superior parietal lobules (PSPL) and the precuneus. These findings suggest that the two representation modes impose different attention demands (symbolic representation being more demanding). 


\subsubsection{Individual Differences Reflected in Structural and Functional Characteristics of Brain Activation}

Neurocognitive research also focuses on individual differences. Neuroimaging studies demonstrate the neural correlates of mathematical difficulties and disabilities (e.g., developmental dyscalculia; Butterworth et al. 2011). At the other end of the continuum, research has also demonstrated connections between intelligence and brain activity related to different cognitive tasks. Neuroimaging research shows that intelligence is associated with the reciprocity of several brain regions within a widespread brain network (Colom et al. 2010; Desco et al. 2011). Another branch of neurocognitive research focuses on the relationship between intelligence and the extent of induced brain activity during cognitive task performance (Jausovec and Jausovec 2000). These studies have led to the formulation of the neural efficiency hypothesis of intelligence, which states that "brighter individuals display lower (more efficient) brain activation while performing cognitive tasks" (Neubauer and Fink 2009, p. 1004). The neural efficiency phenomenon has also been shown to be related to individuals' expertise in a given field (in our case, excellence in mathematics) (e.g., Grabner et al. 2006). At the same time, task difficulty has an effect: The neural efficiency phenomenon is revealed in easy to moderately difficult tasks, whereas when it comes to performing difficult and challenging tasks, more intelligent individuals exhibit higher brain activity (e.g., Neubauer and Fink 2009).

\subsection{Mathematics Education and Educational Neuroscience Can Capitalize on Each Other}

\subsubsection{Goals, Terms, and Tools in the Two Fields of Research}

In the last decade, several publications have been devoted to the various theories in mathematics education (e.g., a volume edited by Sriraman and English 2007). Some debate on the existence and essence of the theories in the field is to be expected. Silver and Herbst (2007) argued that "the development of the grand theory of mathematics education is not simply attainable but desirable for organizing the field" (p. 4), whereas Sriraman and English (2007) questioned the feasibility of creating such a grand theory due to the mathematical, social, and cultural contextualization of mathematics teaching and learning. In our review of the volume (Leikin and Zazkis 2012) we suggested that research in mathematics education is integrated in general education research in two ways. On the one hand, mathematics education is informed by more general theories such as, for example, cognitive sciences, sociology, and anthropology. On the other hand, the recent mathematics education research findings can inform and extend general educational theories. In this paper, I argue that while (in the meantime) mathematics education is not well 
informed by neuroscience research, and findings of mathematics education research are rarely used in neuroscience research, the integration of the two research areas can empower each of them.

Cognitive research in mathematics education has a variety of foci of attention and research methods. These studies include, but are not limited to, learning and understanding of mathematics as related to problem solving, proofs, proving and argumentation, and defining and exemplification. Special attention is given to investigation and modeling activities, while substantial attention is devoted to difficulties and misconceptions, as well as to expertise, creativity, and giftedness. The Handbook of Research Design in Mathematics and Science Education (Kelley and Lesh 2000) emphasizes research designs that are intended to radically increase the relevance of research to actual practice. Examples of such research designs include: teaching experiments, clinical interviews, analyses of videotapes, action research studies, ethnographic observations, software development studies, and computer modeling studies (Kelley and Lesh 2000, p. 18). Schoenfeld (2000) highlighted two main purposes of research in mathematics education. One is a theoretical objective directed at better understanding the nature of mathematical processing as it pertains to thinking, teaching, and learning. The second is an applied objective; that is, to use such understanding to improve mathematics instruction, which ultimately helps realize mathematical giftedness and encourages mathematical creativity. Schoenfeld (2000) stressed that models and theories in mathematics education must have explanatory and predictive power, possess a broad scope, and allow replicability.

As noted in Sect. 21.3 of this paper, neuroimaging research focuses on the underlying brain structures (magnitude of brain activation as well as brain topographies) associated with different types of mental activities in varying population groups. Interestingly, De Smedt and Grabner (2015) identified three types of applications of neuroscience to education: neuro-understanding, neuro-prediction, and neuro-intervention. Neuro-understanding is based on the capacity of neuroscientific research to deepen understanding of mathematical processing at the biological level and thus to inform mathematics education theories regarding typical and atypical development of mathematical competencies. Neuro-prediction opens opportunities to use neuroimaging results to predict learning trajectories. Neuro-intervention includes both (1) the use of brain imaging data to analyze the impact of education on the neural circuitry underlying development of mathematical knowledge and (2) the effect of neurophysiological interventions on mathematical performance or learning. An analysis of exemplary studies of each type can be seen in De Smedt and Grabner (2015).

An interesting connection between the two fields of research can be seen in the parallel between Schoenfeld's (2000) call for the explanatory and predictive powers of the theories in mathematics education and the neuro-understanding and neuro-prediction types of applications of neuroscience to education. In turn, neuroscience has a strong potential for increasing the explanatory and predictive powers of mathematics education theories as well as examining the power of different educational interventions using neuro-intervention Type 1 mentioned above. 
I also would like to suggest the verification power of neuroscience studies, and later in this paper I will illustrate an example of a study (Anderson et al. 2014) that can be categorized as being of a neuro-verification type, even though the authors did not connect their results with mathematics education theories.

Table 21.1 outlines a comparison between the research goals and methodologies in the two fields. I do not include references in the table since each row could include at least a dozen references in each column.

Obviously, neuroscience research on mathematical processing and cognitive research in mathematics education are complementary. They have many features in common, and each field can provide information that cannot be attained by research methodologies in other fields. Clearly, mathematics education research does not address biological data of the kind that is provided by neuroscience. However, behavioral data, collected over long periods of time - related to analysis of processes of mathematical creation (Hadamard 1945), solving mathematical problems of varying complexity and classroom communication and classroom discoursestill are not a part of neuroscience research (excluding eye tracking methodology, which seems to come close to the field of mathematics education research, as mentioned in Note 2 in the Introduction section).

In what follows, I analyze examples of several neurocognitive studies on relatively advanced mathematical processing that suggest interesting and rather clear connections between mathematics education research and neurocognitive research, and I go on to explain these connections. I also provide two examples from a large-scale research project entitled "Multidimensional Investigation of Mathematical Giftedness" performed by the research group of Haifa University's Research and Advancement of Giftedness and Excellence Center (RANGE; Leikin et al. 2013).

Note that I do not provide examples of studies in the fields of number sense and arithmetic. One of the latest comprehensive reviews of neurocognitive studies in this field can be seen in Kaufman et al. (2015). Additionally, de Freitas and Sinclair (2015) provided a critical review of neurocognitive studies on number sense with special attention devoted to studies of dyscalculia. They argued that neurocognitive research, in contrast to mathematics education research, deployed images of numbers with an emphasis on cardinality rather than ordinality and concluded that there is a need for new kinds of neurocognitive research. I take a less critical view, suggesting that integration of the two fields can enable both to benefit from each other.

\subsubsection{Between Pólya and Neuroscience: Discovering the Structure of Mathematical Problem Solving}

Pólya's works (1945/1973) in mathematics education are among the most influential ones in the field of problem solving. His four-step approach to heuristically solving problems included understanding the problem, devising a plan, 
Table 21.1 Brief comparison of cognitive studies in mathematics education and studies in cognitive neuroscience associated with mathematical processing

\begin{tabular}{|c|c|c|}
\hline & $\begin{array}{l}\text { Cognitive studies in mathematics } \\
\text { education }\end{array}$ & $\begin{array}{l}\text { Studies in cognitive neuroscience } \\
\text { associated with mathematical } \\
\text { processing }\end{array}$ \\
\hline $\begin{array}{l}\text { Goals: better } \\
\text { understanding } \\
\text { of }\end{array}$ & $\begin{array}{l}\text { - Skills, expertise, difficulties in } \\
\text { - Numerical operations } \\
\text { - Problem solving processes, } \\
\text { proving, defining, } \\
\text { exemplifying, investigating } \\
\text { - Logical, critical, creative } \\
\text { thinking } \\
\text { - Conceptual understanding } \\
\text { - Teaching, learning, } \\
\text { communication } \\
\text { - Teacher knowledge and skills } \\
\text { - Individual differences }\end{array}$ & $\begin{array}{l}\text { - Brain activation associated with } \\
\text { - Mainly numerical processing } \\
\text { (Subsidizing, enumeration, } \\
\text { approximation, comparison, } \\
\text { arithmetic operations) } \\
\text { - Problem solving (mainly in } \\
\text { arithmetic) } \\
\text { - Training } \\
\text { - Neuro-stimulation } \\
\text { - Individual differences } \\
\text { - Domain-general cognitive } \\
\text { abilities involved in mathematical } \\
\text { processing }\end{array}$ \\
\hline $\begin{array}{l}\text { Mathematical } \\
\text { topics }\end{array}$ & $\begin{array}{l}\text { Broad range of topics, concepts, and } \\
\text { properties from elementary to } \\
\text { university mathematics }\end{array}$ & $\begin{array}{l}\text { Number sense and arithmetic } \\
\text { (mainly) } \\
\text { Relatively advanced mathematics } \\
\text { (a small number of studies) }\end{array}$ \\
\hline $\begin{array}{l}\text { Different } \\
\text { representations }\end{array}$ & $\begin{array}{l}\text { - Numerical, graphical, algebraic, } \\
\text { pictorial, verbal } \\
\text { - Translations between different } \\
\text { representations }\end{array}$ & $\begin{array}{l}\text { - Numerical magnitude } \\
\text { representation (mainly) } \\
\text { - Concrete quality, verbal, } \\
\text { number line } \\
\text { - Symbolic versus pictorial (few) }\end{array}$ \\
\hline $\begin{array}{l}\text { Research } \\
\text { participants }\end{array}$ & $\begin{array}{l}\text { - K-12 } \\
\text { - University students } \\
\text { - Research mathematicians }\end{array}$ & $\begin{array}{l}\text { - Adults (mostly university } \\
\text { students) } \\
\text { - Children (a small number of } \\
\text { studies) } \\
\text { - Research mathematicians (few } \\
\text { studies) }\end{array}$ \\
\hline $\begin{array}{l}\text { Research } \\
\text { conditions }\end{array}$ & $\begin{array}{l}\text { - Laboratory/clinics } \\
\text { - Field experiments, } \\
\text { - Design experiment } \\
\text { - Teaching experiment } \\
\text { - Ethnographical research }\end{array}$ & $\begin{array}{l}\text { - Laboratory } \\
\text { - e.g.: MRI (fMRI), EEG (ERP, } \\
\text { ERD), fNIRs, } \\
\text { - GSR } \\
\text { - Eye tracking }\end{array}$ \\
\hline Research tools & $\begin{array}{l}\text { - Tests } \\
\text { - Written, oral, computerized } \\
\text { - Interviews } \\
\text { - Individual, collective } \\
\text { - Observations } \\
\text { - Written questionnaires } \\
\text { - Self-reports }\end{array}$ & $\begin{array}{l}\text { - Tests } \\
\text { - Computerized (e.g., E-Prime) } \\
\text { - Self-reports }\end{array}$ \\
\hline Tasks & $\begin{array}{l}\text { - Open/closed } \\
\text { - Multiple solutions } \\
\text { - Multiple choice } \\
\text { - Differ in conceptual density }\end{array}$ & $\begin{array}{l}\text { - Very short } \\
\text { - Multiple choice } \\
\text { - Yes/no }\end{array}$ \\
\hline
\end{tabular}


Table 21.1 (continued)

\begin{tabular}{|c|c|c|}
\hline & $\begin{array}{l}\text { Cognitive studies in mathematics } \\
\text { education }\end{array}$ & $\begin{array}{l}\text { Studies in cognitive neuroscience } \\
\text { associated with mathematical } \\
\text { processing }\end{array}$ \\
\hline Measures & $\begin{array}{l}\text { - Behavioral } \\
\text { - Correctness } \\
\text { - P-S/proving strategies } \\
\text { - Critical reasoning, creative } \\
\text { thinking } \\
\text { - Communicative collaborative } \\
\text { and processes } \\
\text { - Teachers' knowledge and } \\
\text { competences }\end{array}$ & $\begin{array}{l}\text { - Behavioral } \\
\text { - Correctness }(\%) \\
\text { - Reaction time } \\
\text { - Neurocognitive } \\
\text { - Magnitude of the brain } \\
\text { activation } \\
\text { - Brain topographies } \\
\text { - Cognitive } \\
\text { - Connections between } \\
\text { mathematical processing of } \\
\text { different types and basic } \\
\text { cognitive functions associated } \\
\text { with these }\end{array}$ \\
\hline
\end{tabular}

carrying out the plan, and looking back. Schoenfeld (1992) suggested somewhat more detailed stages of problem solving that included reading, analyzing, exploring, planning, implementing, and verifying. Pólya and Schoenfeld demonstrated that a close look into these stages can distinguish experts from non-experts in problem solving when the participants are required to cope with a non-standard problem - one for which they do not have a ready-to-use procedure.

Without any connection to Pólya (1945/1973) and Schoenfeld (1992), Anderson et al. (2014) conducted neuroimaging (fMRI) research that was aimed at discovering the stages of mathematical problem solving, the factors that influence the duration of these stages, and how these stages are related to the learning of a new mathematical competence. This study demonstrated that participants went through five major phases when solving a class of problems: (1) Define Phase, where they identified the problem to be solved, characterized by activity in visual attention and default network regions; (2) Encode Phase, where they encoded the needed information, characterized by activity in visual regions; (3) Compute Phase, where they performed the necessary arithmetic calculations, associated with activity in regions active in mathematical tasks; (4) Transform Phase, at which they performed any mathematical transformations, characterized by activation of mathematical and response regions; and (5) Respond Phase, at which they entered an answer, associated with activation in motor regions. Two features distinguished the mastery trials during which participants came to grasp a new problem type. First, the duration of late phases of the solution process increased. Second, there was increased activation in the rostro-lateral prefrontal cortex (RLPFC) and angular gyrus (AG) regions associated with metacognition. This indicates the important contribution of reflection to successful learning.

Obviously, the stages identified by Anderson et al. (2014), which go beyond the task design, are in harmony with the stages devised insightfully by Pólya and Schoenfeld in their works: the define and encode phases correspond to the reading and analyzing stages in Schoenfeld's terms, or to understanding the problem in Pólya's terms. The compute and transform phases correspond to carrying out the 
plan (Pólya). The respond phase corresponds to the looking back or verifying stages (of Pólya and Schoenfeld, respectively). Anderson and colleagues provided biological validation for the big ideas of mathematics education researchers and, in this sense, theirs can be considered a neuro-validation study. At the same time, it provides us with further information about the basic cognitive abilities (visual attention, visual encoding, and motor skills), which are very often overlooked in mathematics education literature. This connection to cognitive processes can be helpful in gaining a better understanding of the effectiveness of educational practices as they are connected to specific cognitive traits. Thus, this study is also of a neuro-understanding type. Moreover, from the point of view of a mathematics educator, connecting the work of Anderson et al. to other works of mathematics educators related to learning and teaching equations can have an added value for the interpretation of the behavioral research results achieved through individual or collective interviews and relevance to the educational practices.

\subsubsection{Mathematical Expertise: Connections Between Advanced Mathematical Processing with Language and Number Sense}

Experts are usually characterized by consistently superior performance on a specified set of representative tasks (Ericson 1996), while expertise reflects a varying balance between deliberate practice and innate differences in capacities and talents. Experts usually have more robust mental imagery, more numerous images, and the ability to make flexible use of different images and focus their attention on appropriate features of problems (Carlson and Bloom 2005). Experts differ from novices in the problem-solving strategies they employ (Schoenfeld 1992). There is consensus that professional mathematicians are experts in mathematics. Poincare (1908) linked the activity of a mathematician to mathematical creation that requires a feeling of mathematical order and mathematical intuition, which, in his opinion, cannot be possessed by everyone. Still, research on mathematical expertise in school students is rare. To the best of my knowledge, the connections between expertise at earlier ages and expertise in research mathematicians remain unexplored.

Neurocognitive research by Amalric and Dehaene (2016) demonstrated connections between numerical processing and relatively advanced mathematical thinking. The researchers performed an investigation into the neuronal origins and consequences of mathematical expertise. They employed fMRI with 15 expert mathematicians and 15 non-mathematicians who had comparable educational backgrounds. The participants were asked to evaluate the correctness of mathematical and non-mathematical statements. The non-mathematical statements referred to general knowledge and could be meaningful or meaningless, while the mathematical statements referred to domains of higher level mathematics: geometry, analysis, algebra, and topology. No differences were found in the cortical 
network activated (a) for all four domains of mathematics examined and (b) in the expert mathematicians when reacting to meaningful vs. meaningless mathematical statements. At the same time, the study revealed a contrast of brain activation measured during the reflection on mathematical statements versus activation associated with reflecting on non-mathematical statements. A direct comparison of the groups revealed that parietal and frontal activation during reflection on mathematical statements was only present in the group of expert mathematicians. The experiment demonstrated that the brain regions employed by expert mathematicians during their reflection on mathematical statements are located outside areas typically associated with language. The findings contradicted previous findings of studies on numerical cognition, which had demonstrated connections between activation evoked by numerical processing and by language. The research by Amalric and Dehaene (2016) shows that language may play a role in the initial acquisition of mathematical competencies and that brain activation during elementary numerical processing and higher level mathematics are connected; they thus demonstrated that advanced mathematical processing is connected to symbolic number processing.

The connection between advanced mathematical processing and number sense can develop awareness of the importance of nurturing mathematical minds from early stages of development. Additionally, these findings can lead to a hypothesis stating that early competencies associated with number processing and numerical operations can constitute predictors of later mathematical expertise and, probably, of mathematical talent. This hypothesis, supported by some self-reports by mathematicians (e.g., Tao 1992) about their first steps of success in mathematics, requires a longitudinal systematic investigation.

\subsubsection{Starting from Theories in Mathematics Education to Enrich Them}

Only a small number of neuroimaging experiments are rooted in theories of science and mathematics education. For example, Babai et al. (2016) explored the effect of mode (discrete/countable vs. continuous perimeters) and the order of presentation on elementary schoolchildren's performance on the "comparison of perimeters" task. They found that providing students with the opportunity to overcome difficulties by altering the mode or order of presentation may lead to improved student performance on the tasks. Their fMRI brain-imaging findings point to two factors that are involved in solving the task correctly: inhibitory control mechanisms and salience. The authors claim that the fMRI brain-imaging results corroborate, validate, and support behavioral findings and, as such, they contribute theoretically and practically to the understanding of reasoning processes and to improved teaching.

Another interesting research study was performed by Tzur and Depue (2014), who examined how task design, rooted in a constructivist theory of learning and 
thinking, may impact adults' brain processing of numerical comparisons. They examined four independent variables: number comparison-whole numbers or unit fractions $(1 / n)$, task sequencing-cueing first by a number or by an operation; distance between the two compared numbers - large $(1>8$ ?) or small $(7>5$ ?), and testing occasion - pre/post a purely conceptual teaching intervention. The study showed that each independent variable had a significant impact on reaction time, whereas the error rate remained invariant. The authors suggest implications for mathematics education and cognitive-neuroscience with rethinking distance effect and the need to amend the limiting notion of fractions as equal-parts-of-whole. Tzur (2015) took it one step further by illustrating differentiated circuitry for comparing whole numbers and unit fractions in support of the hypothesis that a fraction is not merely a simple extension of a whole number.

\subsubsection{Mathematical Giftedness: Designing a Neurocognitive Study Based on Mathematics Education Theories}

Our research group in the RANGE Center at the University of Haifa conducted a study aimed at gaining a better understanding of mathematical giftedness (Leikin et al. 2013). It was motivated by the observation that the evaluation of individuals presented as over-performers or who excel in the field of mathematics is not an easy matter due to the lack of strong definitions of the phenomenon of mathematical giftedness. We also argued that the development of tools for evaluation of individual abilities (especially high abilities) in the field of mathematics is insufficient and that applying brain research to the study of mathematical giftedness seems to be of importance to the attainment of an operative definition of mathematical giftedness and, consequently, to the development of tools that enable researchers to identify mathematical giftedness.

Several distinctions were introduced in the study: First, based on theories of gifted education (e.g., Milgram and Hong 2009), a distinction was made between levels of intelligence ("general giftedness," G, determined by IQ scores higher than 130) and levels of expertise ("excellence in mathematics," EM, determined by high scores in secondary school mathematics). This was applied in the sampling procedure, whereby four research groups were designed by a varying combination of $\mathrm{EM}$ and $\mathrm{G}$ characteristics. Second, based on the theories of mathematics education, a distinction was made between the translations of different representations of mathematical objects required by the task (Kaput 1998) and different areas of mathematics (i.e., algebra and geometry), together with a third distinction between learning-based and insight-based tasks; these distinctions were implemented in the design of the research tools. The task design was determined by Pólya's (1973) theory of problem-solving strategies. Three strategies-understanding the task 
conditions, understanding the question, and verifying the results - constituted the stages of the task design and the corresponding cognitive processes.

The study design led to some exciting discoveries: The distinction between general giftedness and expertise in mathematics proved to be powerful in understanding that these two characteristics, even though interrelated, are different in nature. It was also obvious that using behavioral measures only is insufficient and sometimes misleading.

For example, coping with a function-related task that required translation between graphical and algebraic representations of the functions (Waisman et al. 2014) both at the behavioral (accuracy and reaction time for correct responses) and electrophysiological levels (amplitudes, latencies, and scalp topographies of brain activity identified using the ERP procedure) was affected by students' level of mathematical expertise, with significantly higher accuracy of responses and significantly shorter reaction times among non-gifted students only. Interestingly, students who excelled in school mathematics but were not identified as being generally gifted exhibited the highest electrical brain activity as compared to all the other groups of students. That is, for (relatively) simple learning-based mathematical problems, mathematical expertise appeared to be the main factor that influenced problem-solving performance.

When comparing ERP measures associated with performance of function-based tasks and tasks that involved geometrical inferences (Leikin et al. 2014), we found differences both in the magnitudes and topographies of brain activation at the stage of answer verification (Fig. 21.1). Based on these results, we argue that problem

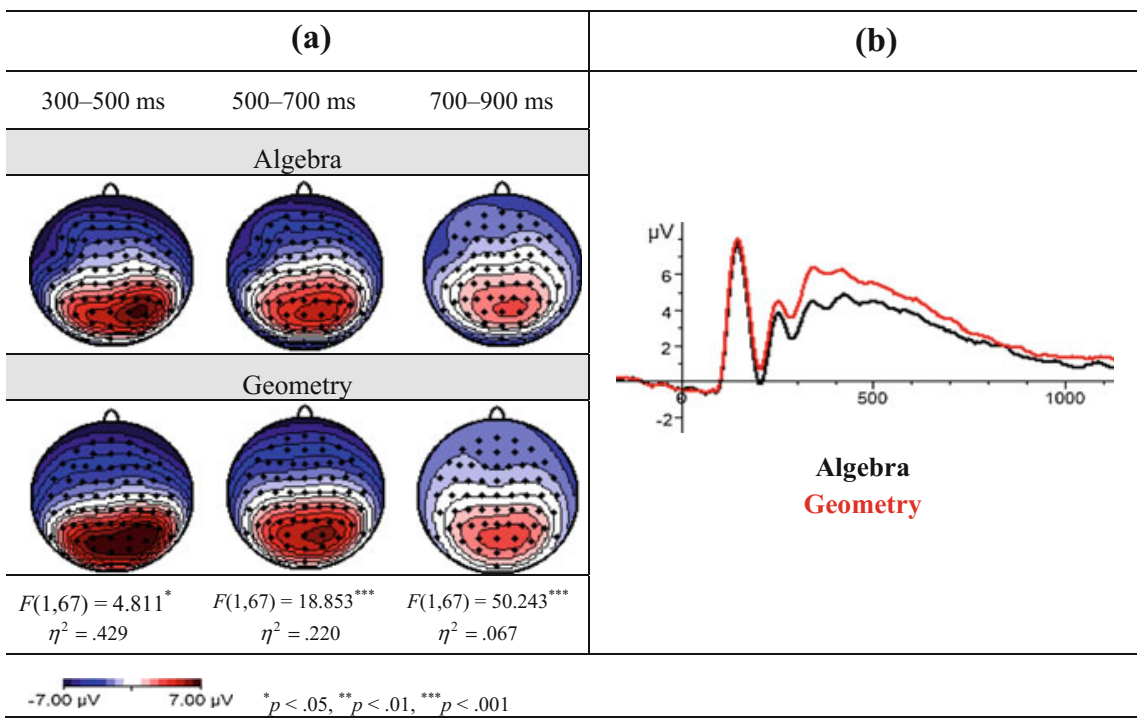

Fig. 21.1 a ERP topographies in the three time frames at the answer verification stage. b Amplitudes in the posterior regions at the answer verification stage 
solving in algebra and geometry, even when requiring a similar translation between visual to symbolic representation, is associated with variant patterns of brain activity as related to different underlying cognitive processes.

The distinction between learning-based and insight-based problems led to additional surprising results (Leikin et al. 2016): behavioral and neurocognitive measures led to somewhat contradictory findings, and thus neurocognitive characteristics provided essential information that was hidden in the behavioral analysis. We found that, contrary to our research hypothesis, expertise in school mathematics affected behavioral measures associated with the insight-based test only, while general giftedness affected accuracy of the responses on both tests. At the same time, as hypothesized, expertise in mathematics and its interaction with general giftedness affected ERP measures associated with solving learning-based problems only, while ERP measures associated with solving insight-based problems appeared to be affected mainly by the $\mathrm{G}$ factor.

Our findings of stronger activation of the PO4-PO8 electrode site (Fig. 21.2) matched findings of Jung-Beeman et al. (2004), who demonstrated the increased activation of the PO8 electrode being associated with the "Aha!" moment. Thus, in Leikin et al. (2016) we raised a hypothesis that our findings on increased activation at the PO4-PO8 electrode site associated with solving insight-based problems indicate that mathematical insight is a specific characteristic unique to generally gifted students. Moreover, our findings expanded upon the previous findings by Jung-Beeman et al. (2004) by showing that students who excel in school mathematics exhibit increased activation of the PO4-PO8 electrode site when they are presented with learning-based mathematical tasks. This finding led to the hypothesis (that opens a window for future studies) that this increase in the absolute ERP

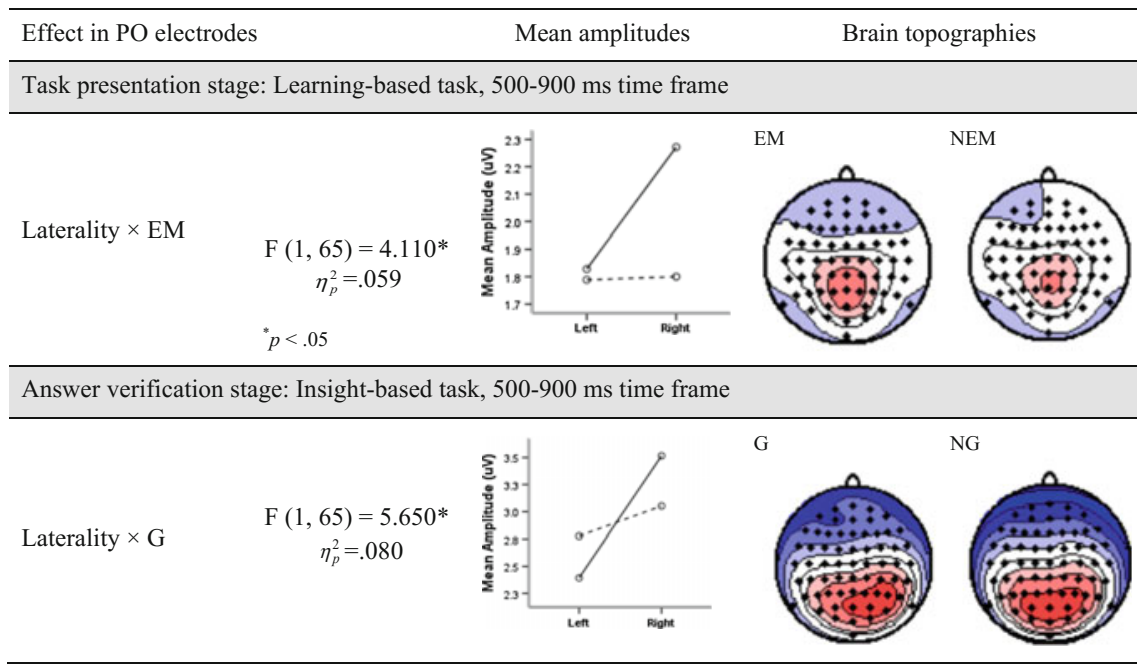

Fig. 21.2 ERP topographies and amplitudes at the stage of answer verification 
amplitudes at the PO4-PO8 electrodes is linked to the ability of experts to predict the problem question based on the problem givens (Schoenfeld 1992). This prediction can also be considered an insight-based process related to learning-based tasks reflected in our findings and, thus, can be considered to be evidence of the insight-related component of problem solving by experts at the stage of understanding the problem.

We connected our findings regarding the strength of electrical potentials evoked in different groups of participants when solving learning-based tasks to the neural efficiency effect (see Sect. 21.3 in this paper and critique by Ansari 2016). We suggest that our findings showed no neuro-efficiency associated with solving insight-based tasks for either G or EM, due to the high difficulty of the task. Furthermore, the effects of the $\mathrm{G}$ characteristic on the cortical topographies associated with solving insight-based problems were explained by the presumably different problem-solving strategies applied by students with different levels of intelligence.

Clearly, our neurocognitive experiment not only validated our initial hypotheses, which were not always supported by behavioral data, but also led to new insights and new hypotheses. First, mathematical expertise and general giftedness are not equivalent constructs. We hypothesized that both of these characteristics are necessary conditions for mathematical giftedness. Second, we realized that externally similar algebra and geometry problems are based on different underlying cognitive processes, as reflected in different brain activation when solving the problems. Third, only ERP data allowed us to develop an understanding that success in solving insight-based problems is a function of general intelligence and is not attained by school mathematical expertise. We believe that further behavioral research is needed to ascertain to what extent classroom culture determines these findings or whether mathematical insight is an innate characteristic of the gifted. Finally, only a neurocognitive experiment enabled us to discover the insight-based component in experts and the problem-solving process inherent in learning-based tasks. This component appears at the stage of understanding the problem, which appears to be insightful for the experts. All these findings were made possible thanks to the careful research design, which was rooted in mathematics education theories and theories of expertise and giftedness. The integration of educational theories in the neurocognitive study allowed us to enhance our knowledge through neuro-discovery and neuro-explanation. At the same time, educational theories allowed for richer interpretation of the research findings.

\subsection{Concluding Comments}

I hope that the analysis performed in this paper demonstrates that mathematics education and cognitive neuroscience can capitalize on each other by increasing validity of findings and mutually providing more substantiated interpretations of findings. Mathematics education can clearly contribute to research design, and 
neuroscience can validate (or perhaps refute) theories in mathematics education and, later, advance the interpretation of research results. Mathematics education initially developed as a branch of cognitive psychology; neurocognitive investigation can enrich mathematics education by contributing to our understanding of the underlying cognitive processes involved in different types of mathematical performance and by explaining the roots of success and difficulties in mathematics learning, proving, problem solving and creative, intuitive, and critical reasoning. To successfully integrate the fields, collaboration between mathematics educators and neuroscientists is crucial. This collaboration should be symmetrical to allow reciprocal enhancement and further development of these two fields of research and, eventually, to allow implementation of the resulting findings in educational practice.

\section{References}

Amalric, M., \& Dehaene, S. (2016). Origins of the brain networks for advanced mathematics in expert mathematicians. Proceedings of the National Academy of Sciences (PNAS), 113, 49094917).

Anderson, J. R., Lee, H. S., \& Finchama, J. M. (2014). Discovering the structure of mathematical problem solving. Neurolmage, 97, 163-177.

Anderson, O. R., Love, B. C., \& Tsai M.-J. (Eds.). (2014). Neuroscience perspectives for science and mathematics learning in technology-enhanced learning environments. International Journal of Science and Mathematics Education, 12(3), 669-696.

Andrá, C., Lindström, P., Arzarello, F., Holmqvist, K., Robutti, O., \& Sabena, C. (2015). Reading mathematics representations: An eye tracking study. International Journal of Science and Mathematics Education, 13(2), 237-259.

Ansari, D., \& Lyonsi, I. M. (2016). Cognitive neuroscience and mathematics learning: How far have we come? Where do we need to go? ZDM Mathematics Education, 48, 379-383.

Babai, R., Nattiv, L., \& Stavy, R. (2016). Comparison of perimeters: Improving students' performance by increasing the salience of the relevant variable. $Z D M, 1-12$.

Bowers, J. S. (2016). The practical and principled problems with educational neuroscience. Psychological Review, 123(5), 600-612.

Butterworth, B., Varma, S., \& Laurillard, D. (2011). Dyscalculia: From brain to education. Science, 332, 1049-1053.

Byrnes, J. P., \& Fox, N. A. (1998). Minds, brains, and education: Part II. Responding to the commentaries. Educational Psychology Review, 10(4), 431-439.

Csíkos, C., Rausch, A., \& Szitányi, J. (Eds.). (2016). Proceedings of the 40th Conference of the International Group for the Psychology of Mathematics Education. China: PME.

De Freitas, E., \& Sinclair, N. (2015). The cognitive labour of mathematicsdis ability: Neurocognitive approaches to number sense. International Journal of Educational Research, $1103,9$.

De Smedt, B., Ansari, D., Grabner, R. H., Hannula, M. M., Schneider, M., \& Verschaffel, L. (2010). Cognitive neuroscience meets mathematics education. Educational Research Review, 5(1), 97-105.

De Smedt, B., \& Grabner, R. H. (2015). Applications of neuroscience to mathematics education. In R. Cohen Kadosh \& A. Dowker (Eds.), The Oxford handbook of numerical cognition. Oxford: Oxford University Press. 
Dehaene, S., Piazza, M., Pinel, P., \& Cohen, L. (2003). Three parietal circuits for number processing. Cognitive Neuropsychology, 20(3-6), 487-506.

Desco, M., Navas-Sanchez, F. J., Sanchez-González, J., Reig, S., Robles, O., Franco, C., \& Arango, C. (2011). Mathematically gifted adolescents use more extensive and more bilateral areas of the fronto-parietal network than controls during executive functioning and fluid reasoning tasks. Neuroimage, 57(1), 281-292.

Grabner, R. H., Ansari, D., De Smedt, B., \& Hannula, M. M. (2010a). Glossary of technical terms in cognitive neuroscience. ZDM-Mathematics Education, 48(3), 461-463.

Grabner, R. H., Ansari, D., Koschutnig, K., Reishofer, G., Ebner, F., \& Neuper, C. (2009). To retrieve or to calculate? Left angular gyrus mediates the retrieval of arithmetic facts during problem solving. Neuropsychologia, 47(2), 604-608.

Grabner, R. H., Ansari, D., Schneider, M., De Smedt, B., Hannula, M. M., \& Stern, E. (2010b). Cognitive neuroscience and mathematics learning. Special Issue of ZDM-Mathematics Education, 48(3).

Grabner, R. H., \& De Smedt, B. (2016). Cognitive neuroscience and mathematics learningrevisited after five years. Special Issue of ZDM-Mathematics Education, 48(3).

Grabner, R. H., Neubauer, A. C., \& Stern, E. (2006). Superior performance and neural efficiency: The impact of intelligence and expertise. Brain Research Bulletin, 69(4), 422-439.

Hadamard, J. (1945). The psychology of invention in the mathematical field. New York: Dover Publications.

Inglis, M., \& Alcock, L. (2012). Expert and novice approaches to reading mathematical proofs. Journal for Research in Mathematics Education, 43(4), 358-390.

Jausovec, N., \& Jausovec, K. (2000). Correlations between ERP parameters and intelligence: A reconsideration. Biological Psychology, 55(2), 137-154.

Kaput, J. J. (1989). Linking representations in the symbol systems of algebra. Research Issues in the Learning and Teaching of Algebra, 4, 167-194.

Kaufman, L., Kucian, K., \& von Aster, M. (2015). Development of the numerical brain. In R. Cohen Kadosh \& A. Dowker (Eds.), The Oxford handbook of numerical cognition. Oxford: Oxford University Press.

Kelly, A. E., \& Lesh, R. A. (2000). Handbook of Research Design in Mathematics and Science Education. Mahwah, NJ: Routladge.

Leikin, M., Waisman, I., \& Leikin, R. (2013). How brain research can contribute to the evaluation of mathematical giftedness. Psychological Test and Assessment Modeling, 55(4), 415-437.

Leikin, M., Waisman, I., Shaul, S., \& Leikin, R. (2014). Brain activity associated with translation from a visual to a symbolic representation in algebra and geometry. Journal of Integrative Neoroscience, 13(1), 35-59.

Leikin, R., Waisman, I., \& Leikin, M. (2016). Does solving insight-based problems differ from solving learning-based problems? Some evidence from an ERP study. Special issue on Neuroscience and Mathematics Education-ZDM-The International Journal on Mathematics Education, 48(3), 305-319.

Muldner, K., \& Burleston, W. (2015). Utilizing sensor data to model students' creativity in a digital environment. Computers in Human Behavior, 42, 127-137.

Neubauer, A. C., \& Fink, A. (2009). Intelligence and neural efficiency. Neuroscience and Biobehavioral Reviews, 33(7), 1004-1023.

Neville, H. J., Coffey, S. A., Holcomb, P. J., \& Tallal, P. (1993). The neurobiology of sensory and language processing in language-impaired children. Journal of Cognitive Neuroscience, 5(2), 235-253.

Norton, A., \& Deater-Deckard, K. (2014). Mathematics in mind, brain and education: A neo-piagetian approach. International Journal of Science and Mathematics Education, 12 (3), 647-667.

Obersteiner, A., Moll, G., Beitlich, J. T., Ciu, C., Schmidt, M., Khmelivska, T., \& Reiss, K. (2014). Expert mathematicians strategies for comparing the numerical values of fractionsevidence from eye movements. In P. Liljedahl, S. Oesterle, C. Nicol \& D. Allan (Eds.), 
Proceedings of the 38th Conference of the International Group for the Psychology of Mathematics Education (Vol. 4, pp. 338-345). Vancouver, Canada: PME.

Poincare, H. (1908/1952). Science and method. New York: Dover Publications Inc.

Pólya, G. (1945/1973). How to solve it. Princeton, NJ: Princeton University.

Schoenfeld, A. H. (1992). Learning to think mathematically: Problem solving, metacognition, and sense-making in mathematics. In D. Grouws (Ed.), Handbook for research on mathematics teaching and learning (pp. 334-370). New York: MacMillan.

Schoenfeld, A. H. (2000). Purposes and methods of research in mathematics education. Notices of the American Mathematical Society, 47, 2-10.

Tao, T. C. S. (1992). Solving mathematical problems: A personal perspective. Geelong: Deakin University Press.

Tzur, R., \& Depue, B. E. (2014). Conceptual and brain processing of unit fraction comparisons: A cogneuromathed study. Proceedings of PME 38, 5, 297-304.

Waisman, I., Leikin, M., Shaul, S., \& Leikin, R. (2014). Brain activity associated with translation between graphical and symbolic representations of functions in generally gifted and excelling in mathematics adolescents. International Journal of Science and Mathematics Education, 12(3), 669-696.

Open Access This chapter is licensed under the terms of the Creative Commons Attribution 4.0 International License (http://creativecommons.org/licenses/by/4.0/), which permits use, sharing, adaptation, distribution and reproduction in any medium or format, as long as you give appropriate credit to the original author(s) and the source, provide a link to the Creative Commons license and indicate if changes were made.

The images or other third party material in this chapter are included in the chapter's Creative Commons license, unless indicated otherwise in a credit line to the material. If material is not included in the chapter's Creative Commons license and your intended use is not permitted by statutory regulation or exceeds the permitted use, you will need to obtain permission directly from the copyright holder.

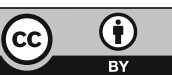

